\title{
Las bibliotecas universitarias españolas y el empleo de vídeos promocionales en línea
}

The use of online promotional videos in Spanish academic libraries

\author{
José Luis HerRera MoriLLAS \\ Departamento de Información y Comunicación, Facultad de Ciencias de la Documentación y la Comunicación, \\ Universidad de Extremadura, Plazuela Ibn-Marwan, s/n, 06071 Badajoz, España; jlhermor@unex.es
}

\begin{abstract}
Resumen
Se presentan los resultados de la recopilación y análisis de 87 vídeos promocionales en línea de 45 bibliotecas universitarias españolas a partir de un cuestionario con 11 campos. El estudio de conjunto abarca aspectos como títulos de los vídeos, ubicación, años de publicación, duración, recursos técnicos, contenidos, etc., y ha permitido clasificarlos y obtener conclusiones sobre la finalidad de estos vídeos, su utilidad, modelo de biblioteca que reflejan, etc.
\end{abstract}

Palabras clave: Promoción. Vídeos. Bibliotecas universitarias. España.

\section{Introducción}

Las bibliotecas dentro de las universidades tienen una misión muy importante. Son uno de los servicios más demandados por profesores y alumnos. Por esta razón, resulta especialmente relevante cuidar su difusión y conocimiento. El objetivo de este trabajo ha sido localizar, recopilar y analizar los vídeos empleados como elemento de promoción en línea por las bibliotecas universitarias españolas.

La promoción se entiende como "toda comunicación de carácter persuasivo dirigida a un público o segmentos y que tiene como fin incentivar a corto, medio o largo plazo el uso de los servicios de información" (Fernández Marcial, 2015). Con el uso de las tecnologías han aparecido nuevos formatos y canales de promoción. Este tipo de promoción se puede relacionar con una parte del marketing (es uno de sus componentes, junto al producto, el precio y la distribución) y también con la web 2.0, pues, estos vídeos suelen estar accesibles en el canal YouTube, una de las herramientas 2.0 donde los usuarios pueden compartir y visualizar vídeos.

Sobre la web 2.0 y las bibliotecas universitarias existen abundantes estudios. Trabajos como los de Alonso Arévalo, et al. (2014); Grande-González y De-la-Fuente-Redondo (2012); o Herrera y Castillo (2011) incluyen actualizados estados de la

\begin{abstract}
The results of the collection and analysis of 87 online promotional videos from 45 Spanish university libraries are presented, using a 11-field record. The general study covers aspects such as the titles of the videos, location, years of publication, duration, technical resources, contents, etc. and it has allowed to classify them and to obtain conclusions on the purpose of these videos, their usefulness, model of library that they reflect, etc.
\end{abstract}

Keywords: Videos. Promotion. University libraries. Spain.

cuestión al respecto. En estos estudios se quiere poner de relieve como las bibliotecas universitarias están empleando las herramientas propias de la web 2.0 (o web social) para comunicarse con sus usuarios. Los estudios abordan la web 2.0 en su conjunto o la aplicación de algunas de sus herramientas (mensajería instantánea; wikis; podcasts; blog; etc.). Parte de estos trabajos son análisis de casos, centrados en determinados países y los resultados suelen hacer referencia al tipo de herramientas o servicios que más y menos se utilizan; los resultados son variados dependiendo del lugar y de la fecha de realización. Estas publicaciones han contribuido a poner en evidencia como el uso de las herramientas 2.0 está cada vez más extendido; o que las más frecuentes en el entorno bibliotecario son "los blogs y las redes sociales... y en menor medida otro tipo de herramientas que se pueden denominar tecnología de segundo nivel, como los marcadores sociales, los podcast y las wikis" (Alonso Arévalo, et al., 2014).

Algo parecido sucede con los trabajos centrados en bibliotecas universitarias españolas: algunos abordan las herramientas en su conjunto (González Fernández-Villavicencio, 2007; Herrera y Castillo, 2011); por ejemplo, el estudio de Grande-González y De-la-Fuente (2012) tuvo por objetivo plasmar una visión general de la aplicación de la web social en las bibliotecas universitarias españolas para ello diseñaron y pasaron 
una encuesta. También, los hay centrados en herramientas concretas, fundamentalmente redes sociales (García Reche, 2016; Linán Maza y Guzmán Pérez, 2016; González García, 2016).

Estudios o experiencias dedicados en exclusiva al empleo del vídeo como ayuda a la difusión y promoción de las bibliotecas universitarias solo se ha localizado uno; y está enfocado a exponer cómo surgió la idea y cómo se realizó un videoclip planteado a modo de carta de presentación de la Biblioteca de la Universidad de Castilla-La Mancha en el campus de Albacete. Lo explican así (Alcón Jiménez, 2016):

Como consecuencia de toda esta explosión documental... se va observando que se produce un desinterés de los usuarios por los instrumentos de información que tradicionalmente se han utilizado. Cada vez es más difícil llamar su atención. Los bibliotecarios hemos de competir en este mundo de la información utilizando nuevas técnicas de marketing para orientar a los alumnos hacia la sociedad del conocimiento que es el lugar en el que realmente les corresponde moverse... Se optó por la realización de un vídeoclip ya que se trata del formato audiovisual más consumido por la juventud, segmento mayoritario de usuarios que frecuentan nuestra biblioteca.

La anterior cita es muy clarificadora para entender la incorporación del vídeo promocional por parte de las bibliotecas universitarias: es uno de los formatos más empleados en la publicidad digital y el favorito de las nuevas generaciones.

Estos vídeos promocionales pueden plantearse como una manifestación de la relación entre la web social y el marketing (González FernándezVillavicencio, 2009):

Las bibliotecas han realizado actividades de marketing a lo largo de los siglos y han buscado al posible lector allá donde éste se encontrara, para ofrecerle sus contenidos y servicios. El marketing es comunicación. La biblioteca se promociona y se comunica a través de los canales que en cada momento ha tenido a su alcance... En un mundo predominantemente presencial, los canales eran unos, hoy día éstos se complementan con los virtuales...

Iniciativas de esta naturaleza son necesarias pues, como indica Tennant (2009), aunque las bibliotecas cuentan con portales web para que los usuarios puedan acceder y conocer sus recursos y servicios, con frecuencia estos usuarios no los conocen y en muchas ocasiones se quedan sin utilizar. En este sentido los vídeos que se estudian en este trabajo son un tipo de recurso que puede conseguir objetivos como: (a) incrementar la visibilidad de la biblioteca en la sociedad mejorando su imagen; (b) difundir sus servicios; y (c) aumentar el uso de los recursos que oferta la biblioteca.

\section{Metodología}

La primera tarea de este trabajo de investigación se ha centrado en localizar los sitios webs de las bibliotecas universitarias españolas. Para ello se han utilizado los recursos Directorio bibliotecas españolas (2019) y Anexo: Universidades de España (2019). Se han visitado todas las universidades (públicas, privadas, presenciales, online, etc.), en total 83 universidades.

Los vídeos se han localizado en los sitios webs de las bibliotecas y en el canal YouTube (https://www.youtube.com/?gl=ES). Se han combinado la estrategia de visualización en línea y el análisis de contenido de los vídeos.

Para analizar la información de cada vídeo se ha realizado el siguiente registro con estos 11 campos (Tabla I):

\begin{tabular}{|c|c|}
\hline Campos & Información \\
\hline Biblioteca & Identificación de la Biblioteca \\
\hline URL & $\begin{array}{l}\text { Dirección del vídeo en internet. Cuando el } \\
\text { vídeo está ubicado en el sitio web de la } \\
\text { biblioteca y en YouTube, se indica } \\
\text { primero la dirección de la web y entre } \\
\text { paréntesis la de YouTube }\end{array}$ \\
\hline Ubicación & $\begin{array}{l}\text { Lugar o apartado dentro del sitio web de } \\
\text { la biblioteca donde se encuentra el vídeo; } \\
\text { y/o si está en YouTube }\end{array}$ \\
\hline $\begin{array}{l}\text { Título } \\
\text { del vídeo }\end{array}$ & $\begin{array}{l}\text { Título que aparece junto al vídeo o en el } \\
\text { inicio del vídeo }\end{array}$ \\
\hline Año & $\begin{array}{l}\text { Año de elaboración o de publicación en } \\
\text { YouTube }\end{array}$ \\
\hline Duración & Duración del vídeo en minutos \\
\hline Contenido & $\begin{array}{l}\text { Breves notas sobre el contenido } \\
\text { del vídeo }\end{array}$ \\
\hline Recursos & $\begin{array}{l}\text { Alusión a los elementos o herramientas } \\
\text { que se emplean en el vídeo: voz en off, } \\
\text { música de fondo, texto, explicaciones de } \\
\text { personas (usuarios, bibliotecarios, etc.) }\end{array}$ \\
\hline $\begin{array}{l}\text { Texto en } \\
\text { YouTube }\end{array}$ & $\begin{array}{l}\text { Descripción textual que se incluye junto a } \\
\text { cada vídeo en el canal YouTube a modo } \\
\text { de presentación del vídeo. En concreto, } \\
\text { se recogen las expresiones utilizadas y } \\
\text { que sirven para conocer la intención o } \\
\text { finalidad de los vídeos: "vídeo de } \\
\text { presentación", "vídeo promocional", etc. }\end{array}$ \\
\hline Realización & $\begin{array}{l}\text { Datos que se mencionan sobre la } \\
\text { realización material del vídeo: la } \\
\text { biblioteca, la universidad, una empresa } \\
\text { externa, etc. }\end{array}$ \\
\hline $\begin{array}{l}\mathrm{N}^{\circ} \text { de } \\
\text { visitas }\end{array}$ & $\begin{array}{l}\text { Número de visitas que han recibido los } \\
\text { vídeos disponibles en YouTube }\end{array}$ \\
\hline
\end{tabular}

Tabla I. Información analizada de los vídeos

En la sede web de la revista se incluye con este artículo el listado de los vídeos localizados, 
ordenados por comunidades autónomas y universidades. De cada uno se indica el título, la URL y el número de visitas recibidas en YouTube. La recopilación de los vídeos y su consulta se llevaron a cabo en marzo y abril de 2019.

\section{Resultados}

El número total de bibliotecas localizadas que disponen de vídeos de promoción es 45 . El número total de vídeos recopilados es 87 . Esta diferencia se explica porque, aunque la mayoría de estas bibliotecas (33 bibliotecas) cuentan con un solo vídeo donde se promociona el servicio de bibliotecas o la biblioteca universitaria, en general, hay otras (12 bibliotecas) que cuentan con más de un vídeo (Tabla II).

\begin{tabular}{lc}
\hline Bibliotecas & $N^{\circ}$ de vídeos \\
\hline Complutense de Madrid & 2 \\
\hline Huelva & 2 \\
\hline Las Palmas & 2 \\
\hline Salamanca & 2 \\
\hline Navarra & 2 \\
\hline Politécnica de Cataluña & 2 \\
\hline Carlos III & 3 \\
\hline Valencia & 3 \\
\hline Barcelona & 4 \\
\hline Alicante & 8 \\
\hline Autónoma de Barcelona & 8 \\
\hline Politécnica de Madrid & 16 \\
\hline
\end{tabular}

Tabla II. Bibliotecas con más de un vídeo

La presencia de más de un vídeo tiene explicaciones diversas: en bibliotecas como las de Huelva y Las Palmas se debe a que tienen vídeos diferentes, uno en la web de la Biblioteca y otro en YouTube. En las bibliotecas de las universidades de Alicante, Carlos III, Navarra y Valencia responde a que cuentan con el vídeo promocional general y otros realizados por algunas de las bibliotecas específicas con las que cuentan la universidad (de campus o de centro). Las bibliotecas de las universidades Autónoma de Barcelona, Barcelona, Complutense de Madrid, Salamanca, Politécnica de Cataluña y Politécnica de Madrid no tienen vídeos generales sólo vídeos de bibliotecas de centro o de campus.

\subsection{Títulos}

Los datos que aportan el análisis de los títulos indican que, sobre todo, se opta por utilizar simplemente el nombre de la biblioteca (75 vídeos). Los otros títulos, más elaborados, se recogen en la Tabla III.

\begin{tabular}{|c|c|}
\hline Universidad-Biblioteca & Título del vídeo \\
\hline $\begin{array}{l}\text { Autónoma de Madrid. } \\
\text { Derecho }\end{array}$ & $\begin{array}{l}\text { "Visita guiada a la Biblioteca de } \\
\text { Derecho" }\end{array}$ \\
\hline $\begin{array}{l}\text { Carlos III. Ciencias } \\
\text { Sociales y Jurídicas }\end{array}$ & $\begin{array}{l}\text { "Conoce tu Biblioteca. } \\
\text { Biblioteca de Ciencias Sociales } \\
\text { y Jurídicas" }\end{array}$ \\
\hline $\begin{array}{l}\text { Carlos III. Rey Pastor } \\
\text { Escuela Politécnica } \\
\text { Superior }\end{array}$ & $\begin{array}{l}\text { "Conoce tu Biblioteca. } \\
\text { Biblioteca Rey Pastor Escuela } \\
\text { Politécnica Superior" }\end{array}$ \\
\hline CEU Cardenal Herrera & “¿Conoces la Biblioteca?” \\
\hline Granada & $\begin{array}{l}\text { "Una biblioteca para ti: Vídeo } \\
\text { promocional de la Biblioteca } \\
\text { Universitaria de Granada" }\end{array}$ \\
\hline Loyola Andalucía & $\begin{array}{l}\text { "Presentación del Servicio de } \\
\text { Biblioteca" }\end{array}$ \\
\hline Málaga & $\begin{array}{l}\text { "Conoce el servicio de } \\
\text { Biblioteca Universitaria de la } \\
\text { UMA?" }\end{array}$ \\
\hline $\begin{array}{l}\text { Politécnica de } \\
\text { Cataluña. Biblioteca } \\
\text { Oriol Bohigas }\end{array}$ & $\begin{array}{l}\text { "Bienvenidos a la Biblioteca } \\
\text { Oriol Bohigas - ETSAB" }\end{array}$ \\
\hline $\begin{array}{l}\text { Pública de Navarra. } \\
\text { Campus de Arrosadia }\end{array}$ & $\begin{array}{l}\text { "Bienvenido a la biblioteca } \\
\text { Universitaria del Campus de } \\
\text { Arrosadia" }\end{array}$ \\
\hline Sevilla & $\begin{array}{l}\text { "INSIDEBUS. Descubriendo la } \\
\text { Biblioteca de la Universidad de } \\
\text { Sevilla" }\end{array}$ \\
\hline $\begin{array}{l}\text { Universidad de } \\
\text { Barcelona. CRAI } \\
\text { Biblioteca de Reserva }\end{array}$ & $\begin{array}{l}\text { "Una visita al CRAI Biblioteca } \\
\text { de Reserva de la Universidad } \\
\text { de Barcelona" }\end{array}$ \\
\hline $\begin{array}{l}\text { Universitat Oberta de } \\
\text { Catalunya }\end{array}$ & $\begin{array}{l}\text { "Bienvenidos a la Biblioteca de } \\
\text { la UOC" }\end{array}$ \\
\hline Vic & $\begin{array}{l}\text { "Bienvenido a la Biblioteca de } \\
\text { la UVic-UCC" }\end{array}$ \\
\hline
\end{tabular}

Tabla III. Algunos de los títulos de los vídeos

Estos títulos incluyen términos o expresiones que dan pista sobre la intencionalidad de los vídeos: atraer a los usuarios hacia la biblioteca:"Bienvenidos", 4 vídeos; "Conoce", 4 vídeos; "Visita", 2 vídeos; "Descubriendo", 1 vídeo; "Presentación", 1 vídeo; y "Promocional", 1 vídeo.

\subsection{Ubicación}

El $45,4 \%$ de los vídeos (40 vídeos) se localizan a la vez en los sitios webs de las bibliotecas y en YouTube. El 40,9 \% (36 vídeos) sólo están accesibles a través de YouTube y el 12,5 \% (11 vídeos) sólo en los sitios webs de las bibliotecas.

Estos datos indican el predominio del uso del canal YouTube. Reflejo de como en las bibliotecas 
universitarias los medios sociales se han convertido en "un aliado que complementa e impulsa el trabajo que se está realizando en la biblioteca universitaria. Acerca a los usuarios a la colección, los servicios, las novedades y hasta al personal bibliotecario..." (Carvajal Cantero, 2016).

Los lugares de los sitios webs donde se ubican los vídeos promocionales suelen ser la página de inicio de la biblioteca o uno de los primeros apartados, bajo las denominaciones de "Presentación" (Lérida, Católica de Valencia, Las Palmas), "Conócenos" (Loyola Andalucía), "Quiénes somos" (Carlos III, Ciencias Sociales y Jurídicas y Escuela Politécnica Superior), "Sobre nosotros" (Pompeu Fabra).

\subsection{Años de publicación}

Los vídeos localizados están realizados entre los años 2008 y 2019 (Tabla IV). Los años que destacan por el número de vídeos son 2011 (19 vídeos), 2018 (15 vídeos) y 2015 (11 vídeos).

\begin{tabular}{lc}
\hline Años & $N^{\circ}$ de vídeos \\
\hline 2019 & 5 \\
\hline 2018 & 15 \\
\hline 2017 & 8 \\
\hline 2016 & 8 \\
\hline 2015 & 11 \\
\hline 2014 & 1 \\
\hline 2013 & 2 \\
\hline 2012 & 5 \\
\hline 2011 & 19 \\
\hline 2010 & 8 \\
\hline 2009 & 2 \\
\hline 2008 & 2 \\
\hline s.a. & 1 \\
\hline
\end{tabular}

Tabla IV. Años de publicación de los vídeos

Para el año 2011 se debe tener en cuenta que se incluyen los 16 vídeos correspondientes a las bibliotecas de la Universidad Politécnica de Madrid.

\subsection{Duración}

En la Tabla $V$ se indican los datos sobre la duración de los vídeos. La duración entre 2 y 4 minutos es la más extendida, abarca el $54 \%$ de los vídeos. Esta breve duración lleva a relacionar estos vídeos con los denominados "microspots y mvídeos" unas de las herramientas digitales aplicadas a la publicidad (Fernández Marcial, 2015).

\begin{tabular}{lc}
\hline Duración de los vídeos (minutos) & $N^{\circ}$ de vídeos \\
\hline Entre 9,39 y 13,03 & $4(4,5 \%)$ \\
\hline Entre 5,41 y 7,41 & $12(13,7 \%)$ \\
\hline Entre 3 y 4,46 & $23(26,4 \%)$ \\
\hline Entre 2,01 y 2,58 & $24(27,5 \%)$ \\
\hline Entre 1,03 y 1,53 & $14(16 \%)$ \\
\hline Entre 0,38 y 0,59 & $10(11,4 \%)$ \\
\hline
\end{tabular}

Tabla V.Tiempo de duración de los vídeos

Los 4 vídeos que destacan por su duración son los siguientes: "Una biblioteca para ti: Vídeo promocional de la Biblioteca Universitaria de Granada" (13,04 minutos); "Historia de la Biblioteca Complutense", Universidad Complutense de Madrid (12,1 minutos); "Biblioteca-CRAI. Recursos y servicios para los estudiantes", Universidad Pablo Olavide (11,23 minutos); y "Biblioteca Universitaria", Universidad de Murcia (9,39 minutos).

\subsection{Recursos}

El estudio de la información incluida dentro del apartado "Recursos" aporta estos datos:

(a) Todos los vídeos emplean imágenes. En su mayoría, hacen uso de la grabación de los espacios bibliotecarios $y$, en algunos casos, utilizan secuencias de fotografías. Ejemplos de vídeos en los que las imágenes son el principal recurso son los de las universidades: Politécnica de Cataluña, Biblioteca Oriol Bohigas ETSAB (imágenes completadas con música y texto); Alicante (imágenes completadas con música y texto en subtítulos); Autónoma de Madrid (imágenes completadas con música y texto); IE Segovia (imágenes completadas con música y alguna información textual). Vídeos que utilizan secuencias fotográficas se han localizado diez:

- Barcelona, CRAI-Biblioteca de Ciencias de la Tierra (música, secuencias de planos con textos explicativos, gráficos, etc.).

- Barcelona, CRAI-Biblioteca de Reserva (secuencia de fotos y subtítulos explicativos).

- Carlos III, Biblioteca de Ciencias Sociales y Jurídicas (música, secuencia de fotos, texto).

- Carlos III, Biblioteca de la Escuela Politécnica Superior (música, secuencia de fotos, texto).

- Complutense, María Zambrano (música, secuencia de fotos, texto).

- Pontificia de Comillas (música, secuencia de fotos, texto).

- Rey Juan Carlos (música, secuencia de fotos). 
- Santiago de Compostela (música, secuencia de fotos).

- Valencia, Biblioteca de Ciencias (música, secuencia de gráficos, textos y fotografías).

- Zaragoza (música, secuencia de fotos, texto).

(b) La música de fondo es muy empleada, aparece en todos los vídeos, menos en 1 (CRAl Biblioteca de Reserva de la Universidad de Barcelona).

(c) La voz en off está presente en 27 vídeos (31 $\%)$ y a través de ella se suelen hacer las explicaciones. Por ejemplo, son habituales los vídeos que combinan, voz en off; música de fondo; e imágenes de espacios, instalaciones; y algún texto que completa la explicación (Huelva, Cantabria, Valladolid, Autónoma de Barcelona, Valencia, etc.).

(d) Las imágenes y/o las explicaciones orales se apoyan con información textual en 74 vídeos $(85$ $\%$ ). Ejemplo de vídeo en el que el texto es el recurso fundamental: CRAI-Biblioteca de Ciencias de la Tierra UB-CSIC (texto y gráficos, acompañados de música e imágenes).

e) Las opiniones y explicaciones a cargo de profesores, bibliotecarios, alumnos, actores, etc. aparecen en 21 vídeos (24,1\%). Existen diferentes variantes:

- Profesores, bibliotecarios y alumnos: a través de sus opiniones y experiencias se expone la utilidad de la biblioteca (Sevilla, etc.).

- Bibliotecarios: las explicaciones están a cargo de varios bibliotecarios (Granada, Pablo Olavide, islas Baleares, etc.).

- Usuarios y bibliotecarios: en la narración se alternan usuarios y bibliotecarios (Navarra, etc.).

- Director de la biblioteca: la explicación del director centra el contenido del vídeo (Málaga, Loyola Andalucía, Oviedo, Salamanca-biblioteca histórica, Burgos, etc.).

- Alumnos-usuarios: los protagonistas son los alumnos y sus opiniones (Barcelona CRAIDerecho, Lérida, Abat Oliva, etc.).

- Actor: un actor hace de alumno y sigue el guión de la voz en off (Pompeu Fabra); un actor caracterizado de mago, sin hablar, nos conduce por la biblioteca, etc. (Rovira i Virgili).

Como ejemplos de vídeos que utilizan todos los recursos anteriores están los de Islas Baleares (música, textos, voz en off, testimonio de tres bibliotecarios, grabaciones de espacios, instalaciones, pantallazos sobre explicación de uso de recursos); Lérida (música, voz en off, explicaciones de usuarios, imágenes de espacios, instalaciones y recursos, textos explicativos).

\subsection{Contenidos}

Un grupo de los vídeos recopilados desempeñan un papel fundamentalmente informativo: suelen ser los que recurren a las imágenes y/o breves explicaciones (bien con textos o voz en off) para mostrar los espacios, recursos, servicios (ejemplos: Huelva, Zaragoza, Islas Baleares, Las Palmas, Cantabria, etc.) o también los que utilizan detalladas exposiciones por parte del personal de la biblioteca (Pablo Olavide, Murcia, etc.) o de alumnos (Abat Oliba, etc.).

En otros vídeos, además, se advierte una intención de promoción, más persuasiva, incidiendo en los "atractivos" y utilidades de la biblioteca. Dentro de esta variante destacan los vídeos que emplean como recurso los testimonios y explicaciones de usuarios, profesores, etc. (ejemplos: Sevilla, Granada, Lérida, Navarra, Carlos III, etc.). En estos casos, se aprecia el uso de cierta implicación emocional mediante el testimonio de las experiencias personales y el fomento de las relaciones interpersonales, un ejemplo claro es el vídeo de la Universidad Carlos III, donde los usuarios se presentan indicando su nombre, estudios, trabajo, etc.

En estas dos modalidades se puede ver reflejada la diferencia entre (Fernández Marcial, 2004):

[...] una comunicación informativa y una promocional. La primera se encamina a informar; en la segunda, la intencionalidad es transmitir un mensaje no con el fin de aumentar el nivel de información sino de modificar la conducta, de llevar a la atención, de trasformar la actitud de los consumidores haciendo que éste traspasen la línea que les convierte en consumidores, en usuarios reales.

El conjunto de vídeos analizados sirve para conocer de cerca las diferentes configuraciones de las bibliotecas universitarias españolas, por ejemplo:

(1) Bibliotecas que explican su única sede en el campus donde se localiza la universidad (Pablo Olavide, Pública de Navarra, etc.).

(2) Bibliotecas que exponen en un vídeo los servicios generales y los distintos centros o sedes en los que se organiza para dar cobertura a los diferentes campus de la universidad (Islas Baleares, Navarra, Alicante, Vigo, Valencia, Autónoma de Barcelona, etc.).

(3) Bibliotecas que dedican vídeos diferentes a las sedes en las que se estructura la biblioteca universitaria (Barcelona, Autónoma de Madrid, Politécnica de Madrid, etc.). 
Finalmente, destacar que los contenidos de los vídeos son de gran ayuda para ilustrar el concepto actual de la biblioteca universitaria:

Algunos son muy apropiados para conocer la figura del CRAI (Centro de Recursos para el Aprendizaje y la Investigación), es decir el servicio universitario concebido para ayudar los profesores y alumnos en "las actividades de aprendizaje, de formación, de gestión y de resolución de problemas sean técnicas, metodológicas y de conocimiento en el acceso y uso de la información" (Área, Hernández y Sancho, 2007). Ejemplo de ello son los vídeos correspondientes a las universidades Pablo Olavide, CEU-Cardenal Herrera, Pompeu Fabra, Lérida o Deusto. Otros vídeos se han elaborado de manera muy pedagógica para mostrar cómo se distribuyen los espacios, servicios y colecciones en el edificio (Pública de $\mathrm{Na}$ varra, Politécnica de Valencia, Politécnica de Cataluña, Biblioteca Oriol Bohigas ETS).

El vídeo de la Biblioteca de Granada es una clara exposición del protagonismo que están alcanzando en el modelo actual de biblioteca universitaria los recursos electrónicos o los recursos para la autoformación. Pero, sobre todo, destaca la exposición que hace sobre los nuevos espacios destinados al trabajo colaborativo o "makerspaces", definidos como comunidades colaborativas en donde se comparten tanto las herramientas como el conocimiento para su creación (Barniskis, 2016, citado por Caridad et al. 2018). Todo ello reflejo de la evolución de la biblioteca, que ha pasado de ser un espacio centrado en la colección al espacio centrado en los usuarios, concebido como un espacio de aprendizaje (González-Fernández-Villavicencio, 2017). Así lo explica Gallo-León (2017):

El libro ya no es el canon al que ajustarse, sino que las bibliotecas se proyectan para acoger usuarios y darles los servicios que necesitan en el entorno más atractivo y acogedor posible.

\subsection{Texto en YouTube}

Los vídeos incluidos en el canal de YouTube suelen tener una breve descripción textual a modo de presentación del vídeo, que es interesante analizar como fuente de información sobre los propósitos de los vídeos. En concreto, se han analizado las siguientes expresiones, presentes en algunas de las descripciones:

- "Visita": 20 vídeos (visita a la biblioteca en 1 vídeo, visita guiada en 4 vídeos y visita virtual, en las 16 bibliotecas de la Politécnica de Madrid).

- "Presentación" (presentación general o de espacios, recursos, servicios, etc.): 14 vídeos.

- "Promocional": 10 vídeos.
- "Conoce": 9 vídeos (conoce el servicio, instalaciones, etc.: 6 vídeos; conoce de cerca: 1 vídeo; ¿conoces la biblioteca?: 1 vídeo).

- "Descubre": 2 vídeos.

- "Trailer": 1 vídeo.

- "Descripción": 1 vídeo.

- "Muestra": 1 vídeo.

- "Recorrido": 1 vídeo.

Estas expresiones, al igual que ocurría con las incluidas en los títulos, evidencian el propósito de atraer a los usuarios hacia la biblioteca.

\subsection{Datos de realización/producción}

La información aportada en los vídeos sobre la realización o producción de los mismos indica estos datos: vídeos elaborados por las bibliotecas, 30; vídeos elaborados por las universidades, 38; vídeos elaborados en colaboración entre las bibliotecas y las universidades, 17; y vídeos que no aportan información, 2.

También hay vídeos que indican el organismo que dentro de la universidad o de la biblioteca ha elaborado el vídeo:

(1) Politécnica de Madrid: Biblioteca en colaboración con el Gabinete de Tele-Educación de la Universidad.

(2) Complutense (vídeo sobre Historia de la Biblioteca Complutense): Biblioteca en colaboración con el Departamento de Estudios e Imagen Corporativa de la Universidad.

(3) Autónoma de Barcelona: Servicio Multimedia de la Universidad.

(4) Burgos: TVUBU.

(5) Huelva: Servicio de Enseñanza Virtual Vicerrectorado de Tecnologías y Calidad.

(6) Islas Baleares: UIB Campus Digital.

(7) Loyola Andalucía: Servicio de Comunicación y Relaciones Laborales de la Universidad.

(8) Oviedo: Área de Innovación de Vicerrectorado de Informática y Comunicaciones. Centro de Conocimiento Principado de Asturias.

(9) Politécnica de Cataluña: Factoría de Recursos Docentes. Área de Soporte TIC a la Docencia.

(10) Rovira i Virgili: Servicio de Recursos Educativos de la Universidad.

(11) Valladolid: Servicio de Medios Audiovisuales de la Universidad. 
Estos datos sirven para constatar la implicación de las propias instituciones (bibliotecas y/o universidades) en la creación de los vídeos. Reflejan que tienen recursos y conocimientos técnicos necesarios y que por ello se puede explicar el incremento en la incorporación de estos vdeos. Al tener capacidad para crearlos es más fácil incorporarlos sin necesidad de acudir a empresas externas, que además supondría un gasto económico mayor.

\subsection{Número de visitas}

De los 76 videos disponibles en el canal YouTube se indica el número de visitas recibidas, según los datos aportados en este canal. En el Listado de vídeos incluido en la edición electrónica de la revista se recoge la cifra exacta para cada vídeo. La Tabla VI también aporta información al respecto. Estos valores se pueden utilizar como un índice para medir el impacto y visibilidad que alcanzan los vídeos. Los 2 vídeos que más llaman la atención por su alto número de visitas son "Biblioteca Universitaria de Deusto. Centro de Recursos para el Aprendizaje y la Investigación" (42.681 visitas) y "Biblioteca", Universidad Carlos III (19.373 visitas). El video de Deusto se centra en el edificio CRAI diseñado por el prestigioso arquitecto Rafael Moneo, lo que ha podido contribuir al alto número de visitas. Por debajo de ellos destacan en visitas: "Universidad de Navarra. La Biblioteca" (7.167 visitas); "Bibliotecas de la Universidad de Zaragoza" (5.638 visitas); "Universidad de Valladolid. Biblioteca" (5.638 visitas); y "Biblioteca ETS Arquitectura" (Universidad Politécnica de Madrid) (5.271 visitas).

\begin{tabular}{ll}
\hline$N^{\circ}$ de visitas & $N^{\circ}$ de vídeos \\
\hline Entre 19.000 y 43.000 & $2(2,6 \%)$ \\
\hline Entre 3.400 y 8.000 & $8(10,5 \%)$ \\
\hline Entre 1.000 y 3.000 & $19(25 \%)$ \\
\hline Entre 400 y 980 & $24(31,5 \%)$ \\
\hline Entre 130 y 340 & $15(19,7 \%)$ \\
\hline Entre 20 y 90 & $7(9,2 \%)$ \\
\hline
\end{tabular}

Tabla VI. Número de visitas de los vídeos

\section{Conclusiones}

El empleo de los vídeos de promoción en línea es un ejemplo de como en España las bibliotecas universitarias siempre han estado en la vanguardia de la incorporación de las posibilidades que brindan las Nuevas Tecnologías. Con la incorporación de estos recursos reflejan el esfuerzo por dar respuesta a una sociedad en la que predomina la cultura mediática y audiovisual.
Los datos aportados en esta investigación ilustran como las bibliotecas universitarias se esfuerzan por acercarse a los usuarios, hablar su lenguaje y atraer su atención. También, como las bibliotecas asumen entre sus tareas la difusión y promoción de sus servicios y recursos adaptándose a los cambios de cada momento y ahora, en concreto, a lo que supone el entorno digital y de internet. Así lo expresa (Juárez-Urquijo, 2014):

En las bibliotecas la comunicación con el usuario que tradicionalmente hemos vehiculado desde nuestros mostradores, está siendo modificada por las nuevas reglas de la sociedad en red... se interpone entre nosotros y los usuarios una tecnología que tenemos que aprender a utilizar y, sobre todo, entender.

Iniciativas en apoyo de la promoción, como la de los vídeos analizados, son muy convenientes para las bibliotecas. Entre otros motivos porque con el auge de lo digital se ha desarrollado cierto sentimiento de pérdida de utilidad y/o de visibilidad dentro y fuera de la biblioteca (Polger y Okamoto, 2013 citado por González-Fernández-Villavicencio, 2016). En este sentido los vídeos pueden fomentar la recuperación de su visibilidad.

Otros beneficios que aportan son:

(a) Mejoran la imagen de la biblioteca y brindan una difusión más amplia.

(b) Sirven de complemento a otros recursos de difusión y promoción con los que cuenta la biblioteca: sitio web, folletos, etc. El lenguaje audiovisual complementa estos mensajes aportando credibilidad y cercanía. Revelan el contenido de la biblioteca, con la fuerza que aportan la imagen y el sonido.

(c) Hacen de ventana o escaparate para las personas que no pueden acudir al edificio de la biblioteca.

(d) Se pueden incorporar con facilidad al estar realizados con herramientas de bajo coste y de fácil manejo.

(e) Sirven de estrategia de comunicación y se deben integrar y complementar con el buen hacer de la biblioteca favoreciendo y potenciando "el acceso tanto a servicios documentales e informativos en el espacio físico, como a los servicios virtuales" (Martínez Díaz, 2014), pues "La comunicación de la oferta de servicios y productos es la garantía de uso y por tanto de alejar a las bibliotecas de una realidad: la infrautilización del uso de los servicios y productos" (Fernández Marcial, 2004).

(d) Las imágenes y grabaciones aportadas son una interesante fuente de información para conocer las diferentes formas de concebir aspectos 
relacionados con la organización y composición de las bibliotecas universitarias, los edificios bibliotecarios y su arquitectura, la distribución de los espacios y servicios, la organización y distribución de las colecciones, el mobiliario y diseño de espacios interiores, y el aspecto y ubicación de herramientas y equipamientos diversos.

Finalmente, indicar que la variedad de vídeos aportados en este trabajo, puede servir de ayuda a aquellas bibliotecas que no cuenten aún con ellos y que se estén pensando en incorporarlos.

\section{Apéndice}

El listado de los vídeos con su información está publicado como documento adjunto en la edición electrónica en el sitio web de la revista.

\section{Referencias}

Abad Hiraldo, R. et al. (2011). Normativa sobre Patrimonio Bibliográfico en las Bibliotecas Universitarias Españolas. // Boletín de la ANABAD. 48:4 (octubre-diciembre 2011) 73-116.

Anexo: Universidades de España (2019). Wikipedia. https://es.wikipedia.org/wiki/Anexo:Universidades_de_Espa\%C3\%B1a (2019-04-01).

Alcón Jiménez, P. et al. (2016). Ven, Ven, a la Biblioteca... ¡Esto es un vertigo...! // RUIDERAe: Revista de Unidades de Información.10 ( $2^{\circ}$ semestre 2016). http://dehesa.une x.es/bitstream/handle/10662/4759/Jornadas Jarandilla UCLM_2.pdf?sequence=1\&isAllowed=y (2019-04-20).

Area, M.; Hernández, F.; Sancho, J.M. (2007). De la biblioteca al centro de recursos para el aprendizaje y la investigación. Barcelona: Editorial Octaedro, 2007.

Alonso Arévalo; et al. (2014). Uso y aplicación de herramientas 2.0 en los servicios, producción, organización y difusión de la información en la biblioteca universitaria. // Investigación bibliotecológica. 28:64 (2014) 51-74.

Barniskis, S. C. (2016). Access and Express: Professional Perspectives on Public Library Makerspaces and Intellectual Freedom. // Public Library Quarterly. 35:2, 103-125. https:// doi.org/10.1080/01616846.2016.1198644 (2019-04-14).

Caridad Sebastián, M.; García López, F.; Martínez Cardama, S.; Morales García, A.M. (2018). Bibliotecas y empoderamiento: servicios innovadores en un entorno de crisis. // Revista Española de Documentación Científica. 41:2 (2018). https://doi.org/10.3989/redc.2018.2.1486 (2019-04-12).

Carvajal Cantero, M.A. et al (2016). Marketing bibliotecario: 10 campañas exitosas de la Biblioteca Universitaria de Huelva en los medios sociales. // Boletín de la Asociación Andaluza de Bibliotecarios. 31:111 (2016) 147-159. https://www.aab.es/app/download/26806731/BibliotecasBoletín-111-147-159.pdf (2019-04-12).

Directorio bibliotecas españolas (2019) http://directoriobibliotecas.mcu.es/dimbe.cmd?apartado=portada (2019-04-01).

Fernández Marcial, V. (2015). Marketing mix de servicios de información: valor e importancia de la $\mathrm{P}$ de producto. // Bibliotecas. Anales de investigación. 11:11 (2015) 64-78. http://eprints.rclis.org/28770/ (2019-04-11).

Fernández Marcial, V. (2004). Promoción de los servicios de la biblioteca: un enfoque desde el marketing no convencional. // Biblios. 5:20 (octubre-diciembre 2004). http://eprints.rclis.org/5842/ (2019-04-21).
Gallo-León, J.-P. (2017). Marketing y espacios bibliotecarios, condenados a encontrarse. // Anuario ThinkEPI. 11 (2017) 579. http://dx.doi.org/10.3145/thinkepi.2017.10 (2019-03-19).

García Reche, G. (2016). ¿Por qué las redes sociales y los mecanismos de comunicación on line en la biblioteca universitaria? // Boletín de la Asociación Andaluza de Bibliotecarios. 31:111 (enero-junio 2016) 179-187. https://www. aab.es/publicaciones/bolet\%C3\%ADn-aab/bolet\%C3\%A Dn-111/ (2019-03-14).

González Fernández-Villavicencio, N. (2009). Bibliotecas y marketing en red. // $\mathrm{BiD}$ : textos universitaris de biblioteconomía i documentació. 23 (diciembre 2009). http://bid.ub.edu/23/gonzalez2.htm (2019-04-10).

González Fernández-Villavicencio, N. (2007). Biblioteca 2.0 en España (el camino recorrido). // Boletín de la Asociación Andaluza de Bibliotecarios. 22:86-87 (2007) 29-46. https://dialn et.unirioja.es/servlet/articulo?codigo=2544094 (2019-04-14).

González Fernández-Villavicencio, N. (2017). Espacios físicos de la biblioteca universitaria en el nuevo ecosistema de aprendizaje. // Anuario ThinkEPI. 11 (2017) 109-118. https://doi.org/10.3145/thinkepi.2017.14 (2019-03-18).

González Fernández-Villavicencio, N. (2016). Un plan de marketing no es un plan de comunicación. //Boletín de la Asociación Andaluza de Bibliotecarios. 31:111 (enero-junio) (2016) 8-26. https://www.aab.es/publicaciones/bolet\%C3\%ADn-aab/bolet\%C3\%ADn-111/ (2019-03-14).

González García, J.A. (2016). Aspectos emocionales en las redes sociales. Como crear una comunidad desde la práctica. // Boletín de la Asociación Andaluza de Bibliotecarios. 31:111 (enero-junio 2016) 49-63. https://www.aab. es/publicaciones/bolet\%C3\%ADn-aab/bolet\%C3\%ADn111/ (2019-04-02).

Grande-González, P.; De-la-Fuente-Redondo, P. (2012). Bibliotecas universitarias españolas en la web social. // El profesional de la información. 21:6 (noviembre-diciembre) (2012) 577-584. http://dx.doi.org/10.3145/epi.2012 .nov.04 (2019-04-02).

Herrera Morillas, J.L.; Díaz Castillo, A. (2011). Bibliotecas universitarias 2.0. El caso de España. // Investigación Bibliotecológica. 25:55 (septiembre-diciembre 2011) 175-200. http://dx.doi.org/10.22201/iibi.0187358xp.2011.55.32861 (2019-03-22)

Juárez-Urquijo, F. (2014). La biblioteca ante los nuevos retos de la comunicación: el bibliotecario desorientado. // Anuario ThinkEPI. 8 (2014) 122-125. https://recyt.fecyt.es/index.php/ThinkEPI/article/view/29565 (2019-04-07).

Liñán Maza, C.; Guzmán Pérez, C. (2016) Las redes sociales en la Biblioteca Universitaria de Córdoba. // Boletín de la Asociación Andaluza de Bibliotecarios. 31:111 (enero-junio 2016) 95-108. https://www.aab.es/publicaciones/bolet\%C3\%ADn-aab/bolet\%C3\%ADn-111/ (2019-04-02).

Martínez Díaz, A. (2014) Las Estrategias de Comunicación en la Biblioteca Regional de Murcia: merchandising y e-merchandising. // Cuadernos de Gestión de Información. 4 (2014) 139-154. http://revistas.um.es/gesinfo/article/view/ 220731 (2019-03-28).

Polger, M.A.; Okamoto, K. (2013). Who's spinning the library? Responsibilities of academic librarians who promote. // Library Management. 34:3 (2013) 236-253. https://doi.org/ 10.1108/01435121311310914 (2019-04-18).

Tennant, R. (2009). Descripció i accés en el segle XXI. // BiD: textos universitaris de biblioteconomia i documentació. 22 (juny 2009). http://bid.ub.edu/22/tennant1.htm (2019-04-28).

Enviado: 2019-04-24. Segunda versión: 2019-06-05. Aceptado: 2019-06-06. 